\title{
A Cheap and Efficient Way to Slip Electrodes
}

by James M. Ford

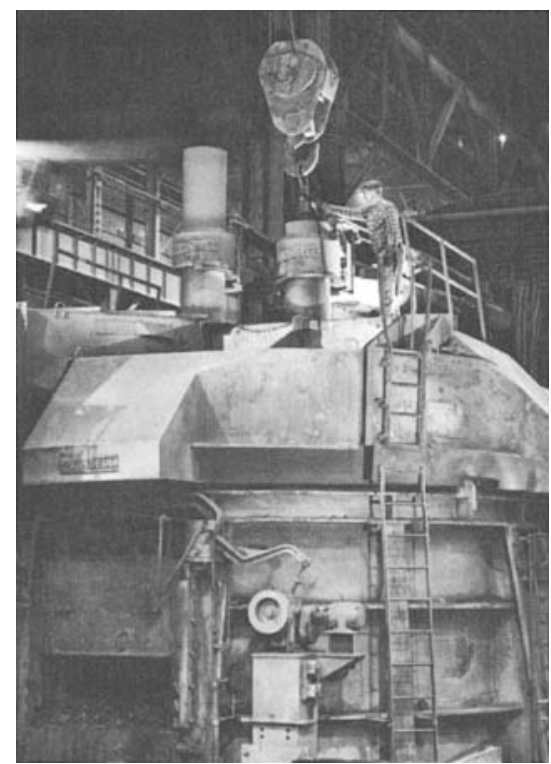

Fig. 1-Old method of slipping electrodes.

Climbing up a ladder to the roof of an electric arc furnace to slip electrodes is a hot, miserable job. Not only that, it is time consuming. About a year ago, the writer visited the electrode manufacturing plant of Union Carbide Corp. in Tennessee. One of the things observed while touring the plant was a rig for picking up an electrode while it was in the vertical position, moving it to another station, and setting it down still in the vertical position. It was immediately decided that some type of material handling device to slip electrodes would save time for our company, as well as wear and tear on the man.

The engineering department at Midvale-Heppenstall developed an automatic safety tong to handle the 18 in. electrodes on a 50-ton furnace and the $20 \mathrm{in}$. electrodes on a $100-$ ton furnace. A quick connect-disconnect adaptor to fit on the same tongs to handle 16 in. electrodes on a 30 -ton furnace is now being designed.

This set of automatic tongs also provides a simplified method of extracting a broken electrode from the charge during initial melt down, which can be frustrating and time consuming when using a chain or sling.

JAMES $M$. FORD is with Midvale-Heppenstall Co., Philadelphia, $\mathrm{Pa}$.

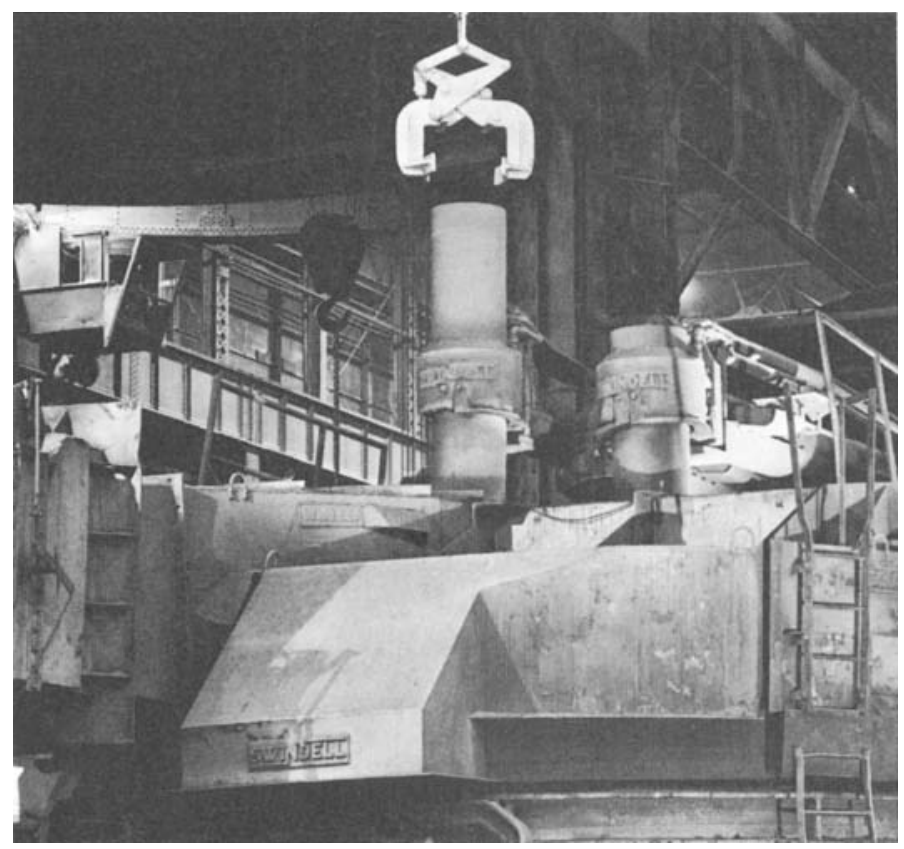

Fig. 2-Tongs being maneuvered for position.

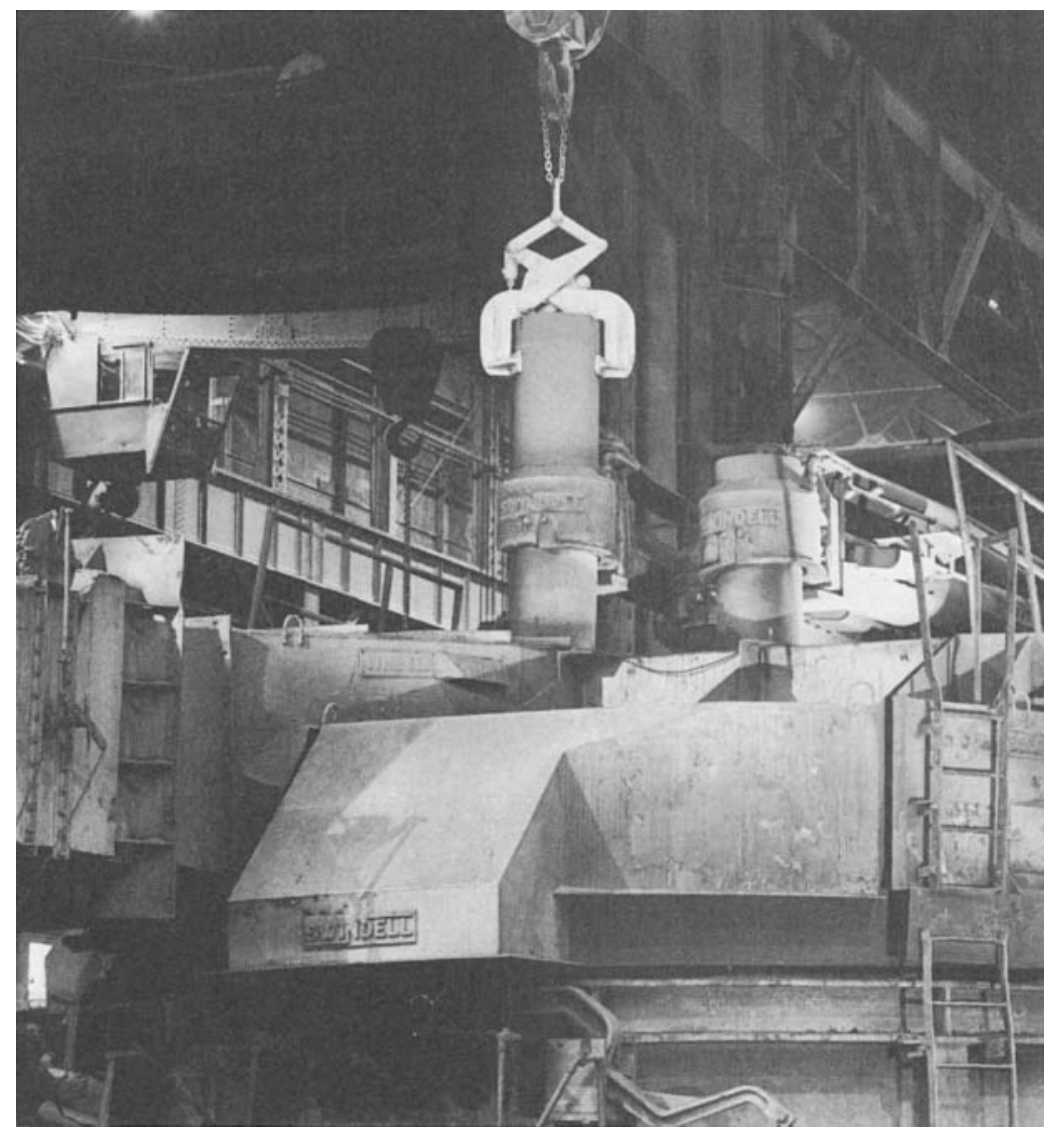

Fig. 3-Tongs placed for gripping and slipping electrodes. 